\title{
Knowledge Towards Antenatal Care and Service Utilization Among Women in Fiche Town, North Shewa, Ethiopia
}

\author{
Rebik Shukure $^{1, \text { * }}$, Tesfahun Simegnew ${ }^{2}$ \\ ${ }^{1}$ Department of Nursing, Faculty of Health Science, Salale University, Fiche, Ethiopia \\ ${ }^{2}$ Department of Nursing, Collage of Health Science, Addis Ababa University, Addis Ababa, Ethiopia
}

Email address:

rebikshukure92@gmail.com (R. Shukure)

${ }^{*}$ Corresponding author

\section{To cite this article:}

Rebik Shukure, Tesfahun Simegnew. Knowledge Towards Antenatal Care and Service Utilization Among Women in Fiche Town, North Shewa, Ethiopia. Advances in Materials. Vol. 4, No. 1, 2018, pp. 1-5. doi: 10.11648/j.ajp.20180401.11

Received: June 10, 2017; Accepted: June 29, 2017; Published: January 8, 2018

\begin{abstract}
Maternal mortality is the highest in sub- Saharan Africa, where the life time risk of death from pregnancy related conditions is 1 in 16, compared with 1 in 2800 in developed countries, In Ethiopia, like other sub Saharan Africa countries, maternal and infant mortality remains to be a problem of public health importance. There are 350 maternal deaths for every 100000 live births. Antenatal care, the care that the women receive during pregnancy, helps to ensure healthy outcome for women and new born. A community based cross sectional study design was conducted. Systematic random sampling technique was used. A total of 345 women who delivered in the 5 years before the date of survey were interviewed. Two hundred twenty three $(64.6 \%)$ women were reported to have received antenatal care at least once during their last pregnancy. Of these, $89(39.9 \%)$ had four or more antenatal care follow ups during their last pregnancy. This is low coverage compared to other developing country. The government sector and health worker need to give great attention for antenatal care.
\end{abstract}

Keywords: Factors, Utilization, Antenatal Care

\section{Introduction}

Antenatal care (ANC), along with family planning, skilled delivery care and emergency obstetric care is a key element of the package of service aimed at improving maternal and new born health [1].

Antenatal care (ANC) refers to a care before birth, and includes education, counseling, screening and treatment to monitor and promote the well being of the mother and fetus [1].

Antenatal care is the care a woman receives throughout her pregnancy and is important in helping to insure a healthy pregnancy state and safe children. The objective of ante natal care is to ensure that every wanted pregnancy results in the delivery of a healthy baby without impairing the mother's health (2).

Ante natal care is one of the most effective health interventions for preventing maternal morbidity and mortality particularly in places where the general health status of women is poor. The ante natal care period presents an important opportunity for identifying threats to the mother and unborn baby's health as well as for counseling on nutrition, birth preparedness, delivery care and family planning options after the birth; beyond that early utilization of antenatal service is the corner stone for the effective implementation of HIV (PMTCT) program [3].

Lack of relevant and high quality antenatal care is still a major concern for many pregnant women in low and middle income countries in Africa and Asia, where the number of women who seek routine antenatal care is low and they often do so only in late pregnancy [4]. Direct obstetric complications (hemorrhage, sepsis, unsafe abortion, hypertensive disorders, obstructed labor and other like embolism) can contribute for up to $80 \%$ of maternal death [5].

The UN millennium Development Goal (MDG) on maternal health aims to reduce the number of women who die in pregnancy and child birth by three-quarters between 1990 and 2015 [6].

Maternal mortality is the highest by for in sub- Saharan 
Africa, where the life time risk of death from pregnancy related conditions is 1 in 16 , compared with 1 in 2800 in rich countries [7].

In Ethiopia, the level of maternal and infant mortality rate is the highest in the world. There are 676 maternal deaths for every 100000 live births, infant mortality rate was 59 per 1000 live births and the neonatal mortality rate was 37 deaths per 1000 live births [8].

According to the EDHS 2011, 34\% of pregnant mothers who give birth in the five years preceding the survey received antenatal care from a skilled provider that is from a doctor, nurse, midwifes for their most recent birth. About six in every ten Ethiopian women (57\%) did not receives any antenatal care for their last birth in the five years preceding the survey; about $10 \%$ of women were assisted by health professionals for their most recent birth [8].

Urban women are almost three times more likely than rural women to receive antenatal care from a skilled provider, $76 \%$ of women residing in urban areas received ANC service from a skilled provider for their last birth compared to $26 \%$ of women in rural areas [8].

A community based cross sectional study done in Hadiya zone of southern Ethiopia from January -February 2009 showed that antenatal care service utilization in the study area was $86.3 \%$ from a total of 691 women who give birth at list once within the last five years before the survey [9].

\section{Methodology}

\subsection{Study Design}

A community based cross sectional study was conducted to assess knowledge, utilization and associated factors affecting women towards ANC use in Fiche town, North Shewa, Ethiopia.

\subsection{Study Area and Period}

The study was done in Fiche town. Fiche is a town located in North Shewa zone which is found in Oromiya National Regional State. The district located $115 \mathrm{KM}$ away from Addis Ababa, the capital of Ethiopia. According to the information get from town administrative office Fiche town has the total population of 39910 , of which 18774 are males and 21136 are females, and from these females 8832 are in the age of reproductive age group. The study was conducted from November to May.

\subsection{Population}

\subsubsection{Source Population}

All households in Fiche town

\subsubsection{Study Population}

All households that have women of reproductive age group were included.

\subsection{Inclusion Criteria and Exclusion Criteria}

\subsubsection{Inclusion Criteria}

Women who are currently pregnant and have children under 5 years old

Women who have no children but pregnant before

\subsubsection{Exclusion Criteria}

Women who have no child and not pregnant before, and Less than 15 years old and greater than 49 years old

\subsection{Sample Size Determination}

Sample size was determined by using a formula for estimating a single population proportion with confidence interval of $95 \%, 5 \%$ marginal error, the estimated proportion of taken as $34 \%$ which is the prevalence of ANC utilization from EDHS, a total of 345 participant were required for the study. The study subjects were selected by using systematic random sampling technique with the $K$ value of 25 until the study participants was selected.

\subsection{Operational Definitions}

Knowledgeable; women who answered $50 \%$ of the questions correctly

ANC service Utilization; having at least 1 visits of health facility for check purpose during pregnancy.

\subsection{Data Processing and Analysis}

The collected data was checked for completeness. SPSS version 20 statistical software was employed for data entry and analysis. All data were coded in terms of number. The analysed data was described by table, percentage and graph, all of which are instruments for interpretation of the collected data.

\subsection{Data Quality Assurance}

Every day after data collection, questionnaires was reviewed and checked for completeness and relevance by principal investigation. The principal investigators had closely followed the day to day data collection process and insured completeness and consistency of questionnaire administered each day. Data was coded, entered, cleaned and analysed by using SPSS version 20 .

\subsection{Ethical Consideration}

Letter of approval was obtained from the advisor and the department. Then it was submitted to ethical review committee of AAU for ethical review. The permission letter from the ethical review committee was submitted to $\mathrm{CBE}$ coordination office of AAU to grant letter or cooperation. The letter of cooperation was given to each of the Keble of Fiche town, Fiche health bureau and administrative office. The respondents were informed about the objective and purpose of the study. They had the rights to refuse or withdraw from the study. 


\section{Result}

\subsection{Socio Demographic Characteristics of Study Participants}

A total of 345 women who delivered in the 5 years before the date of survey were interviewed. Majority of the respondents $183(53.0 \%)$ were in the age of 24-34. The mean age of the respondents was 27.2 (SD +/- 5.91) years. 206 (59.7\%) Amhara by ethnicity, 272 (78.8\%) and 63 (18.3\%) were followers of Orthodox Christian and Muslim religions respectively. Of the total $308(89.3 \%)$ of the respondents were married currently. About half, 175 (50.7\%) were illiterate while $94(27.2 \%)$ attained primary education and the remaining $76(22.0 \%)$ have attained a secondary and above level of education. Occupation wise, the over whelming majority $243(70.4 \%)$ were housewives. Majority of the respondents $309(89.6 \%)$ had 5 and below children, while 36 $(10.4 \%)$ had above 5 children. Among the respondents majority $158(45.8 \%)$ were pregnant currently, while 146 $(42.3 \%)$ were breast feeding. About 134 (38.8\%) of the respondents had family income of 500-1000 birr, while the remaining $70(20.3 \%)$ and $141(40.9 \%)$ had income of below 500 birr and above 1000 birr respectively (table 1).

Table 1. Sociodemographic characteristics of study participants, Fiche town, North Shewa, Ethiopia.

\begin{tabular}{|c|c|c|c|}
\hline Variable & & Frequency & Percent \\
\hline \multirow{3}{*}{ Age } & $15-24$ & 115 & $33.3 \%$ \\
\hline & $25-34$ & 183 & $53.0 \%$ \\
\hline & $35-49$ & 47 & $13.6 \%$ \\
\hline \multirow{3}{*}{ Educational status } & Can't read and write & 175 & $50.7 \%$ \\
\hline & Primary school & 94 & $27.2 \%$ \\
\hline & Secondary school and above & 76 & $22.0 \%$ \\
\hline \multirow{4}{*}{ Job } & Government employee & 49 & $14.2 \%$ \\
\hline & merchant & 24 & $7.0 \%$ \\
\hline & Day worker & 14 & $4.1 \%$ \\
\hline & Other & 15 & $4.3 \%$ \\
\hline \multirow{4}{*}{ Religion } & Orthodox & 272 & $78.8 \%$ \\
\hline & Muslim & 63 & $18.3 \%$ \\
\hline & Protestant & 10 & $2.9 \%$ \\
\hline & other & - & - \\
\hline \multirow{4}{*}{ Ethnicity } & Amhara & 206 & $59.7 \%$ \\
\hline & Tigray & 32 & $9.2 \%$ \\
\hline & Oromiya & 102 & $29.5 \%$ \\
\hline & Other & 5 & $1.5 \%$ \\
\hline \multirow{3}{*}{ Marital status } & Married & 308 & $89.3 \%$ \\
\hline & Single & 21 & $6.1 \%$ \\
\hline & Divorced & 16 & $4.6 \%$ \\
\hline \multirow{2}{*}{ No. of children in the family } & $<5$ & 309 & $89.6 \%$ \\
\hline & $>5$ & 36 & $10.4 \%$ \\
\hline \multirow{4}{*}{ Income per month } & $<500$ & 70 & $20.3 \%$ \\
\hline & $500-1000$ & 134 & $38.8 \%$ \\
\hline & $1000-1500$ & 109 & $31.6 \%$ \\
\hline & $>1500$ & 32 & $9.3 \%$ \\
\hline Current status & Other & 41 & $11.9 \%$ \\
\hline \multirow{2}{*}{ Listening radio or $\mathrm{TV}$} & Yes & 180 & $52.2 \%$ \\
\hline & No & 165 & $47.8 \%$ \\
\hline
\end{tabular}

\subsection{Frequency Distribution of ANC Knowledge and Utilization}

Out of the 345 studied women, the majority $223(64.6 \%)$ received ANC at least once but $122(35.4 \%)$ reported that they did not attend ANC for their last pregnancy. Among women who had ANC follow up 84 (37.7\%) attained the recommended four ANC visits by WHO. About 208 (93.3\%) of women received ANC follow up from health centres. The majority 160 (71.7\%) reported that urinalysis and VDRL was done and FeSO4 and TT vaccine were given to them. The majority 313 (90.7\%) of women had good knowledge regarding ANC. 116 (35.5\%) women reported that their source of information about ANC service were health institutions and $103(31.5 \%)$ said health extension workers. 
Table 2. Frequency distribution of ANC knowledge and utilization of women in Fiche town 2015/16.

\begin{tabular}{|c|c|c|c|}
\hline Variables & & Frequency & Percent \\
\hline \multirow{2}{*}{ ANC visit for previous pregnancy } & Yes & 223 & $64.6 \%$ \\
\hline & No & 122 & $35.4 \%$ \\
\hline \multirow{5}{*}{ No. of visits } & 1 times & 36 & $16.1 \%$ \\
\hline & 2 times & 37 & $16.6 \%$ \\
\hline & 3 times & 61 & $27.4 \%$ \\
\hline & 4 times & 84 & $37.7 \%$ \\
\hline & $>4$ times & 5 & $2.2 \%$ \\
\hline \multirow{3}{*}{ ANC visit site } & Hospital & 10 & $4.5 \%$ \\
\hline & Health center & 208 & $93.3 \%$ \\
\hline & Health post & 5 & $2.2 \%$ \\
\hline \multirow{6}{*}{ Things done during ANC } & Urinalysis & 3 & $1.3 \%$ \\
\hline & Feso4 & 13 & $5.8 \%$ \\
\hline & TT vaccine & 39 & $17.5 \%$ \\
\hline & VDRL & 1 & $0.4 \%$ \\
\hline & All things done & 160 & $71.7 \%$ \\
\hline & Nothing done & 7 & $3.3 \%$ \\
\hline \multirow{2}{*}{ Over all knowledge } & Poor & 32 & $9.3 \%$ \\
\hline & Good & 313 & $90.7 \%$ \\
\hline \multirow{2}{*}{ Ever heard about ANC? } & Yes & 327 & $94.8 \%$ \\
\hline & No & 18 & $5.2 \%$ \\
\hline \multirow{5}{*}{ Source of information } & Health institution & 116 & $35.5 \%$ \\
\hline & $\mathrm{TV}$ or radio & 74 & $22.6 \%$ \\
\hline & Traditional birth attendant & 1 & $0.3 \%$ \\
\hline & Health extension workers & 103 & $31.5 \%$ \\
\hline & Friends & 33 & $10.1 \%$ \\
\hline
\end{tabular}

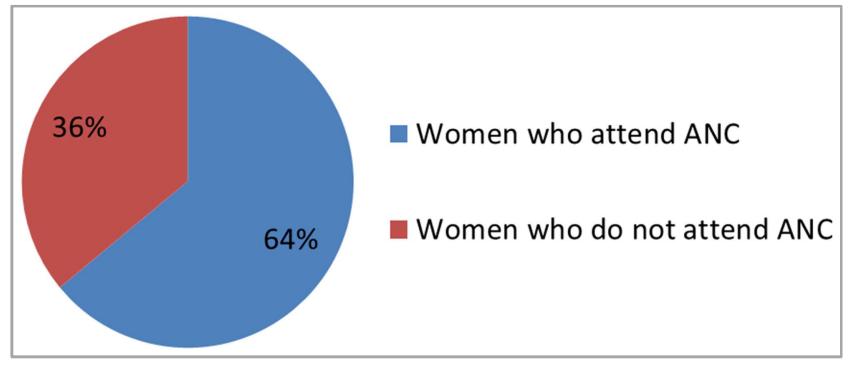

Utilization recorded.

Figure 1. Show Utilization recorded.

\section{Discussions}

A community based cross sectional survey conducted in utilization of antenatal care among reproductive age group women (15-49) years in urban squatter settlement of Karachi from 295 married women of resident of Rehrigoth of women $152(51 \%)$ received antenatal care in their most recent pregnancy while $143(49 \%)$ did not receive antenatal care. Among those who did not receive antenatal care, 28\% reported that they did not know it was required, $10 \%$ were not advised by anyone, $8 \%$ said that they did not have permission from home, $10 \%$ found that facility to be far away, $7 \%$ that transport was not available and $37 \%$ did not have any reason. This is lower than ANC attendant of fiche women this may be due to awareness creation done by health extension worker in the area $[10,11]$.

Across sub Saharan Africa there is a wide variation in ANC attendance; although $71 \%$ of pregnant women attend formal ANC at least one, only $44 \%$ attend ANC four or more times this is higher than the current result. The reason may be due to high coverage of ANC [12].

A community based cross sectional survey conducted in western province, Kenya among the 979 pregnant women in the survey, $59 \%$ had attend ANC clinics while $39 \%$ had not [13].

A descriptive research design using stratified sampling technique done on osun state Nigeria out of 102 pregnant women $58(56.9 \%)$ attend ANC regularly while $40(39.2 \%)$ occasionally, only $4(3.9 \%)$ never attend. Majority of the respondents $56(57.1 \%)$ booked for antenatal care in the first trimester, $25(25.1 \%)$ in the second trimester and $17(17.4 \%)$ in the third trimester. The study also showed that majority of the respondents identified affordability of antenatal care service, schedule of ANC, lack of knowledge about the existing service in ANC and Husband's acceptance of the service rendered as the major factors influencing its utilization [14].

Another study conducted in Kenya shown 90\% percent of them visited an ANC at least once; among the attendees, who could recall when they first attended, 14\% started ANC visits in the first trimester, $64 \%$ started in the second trimester, and $23 \%$ in the third trimester. This result is higher due to high coverage of ANC [15].

A cross sectional study done in Yeme special woreda south west Ethiopia in April 2008 among 651 women who have had a birth 12 months prior to the survey, 179 (28.5\%) women were reported to have receive antenatal care at least once during their last pregnancy; of these $88(49.2 \%)$ women made the first antenatal care visit during their second trimester, while $52(29 \%)$ had four or more antenatal care follow ups during their last pregnancy (16). The level of antenatal care utilization were also found to be high among women with higher economic status, better education, few 
children, married women and employed women [16].

Several studies conducted in developing countries on demographic and socio cultural factors influencing use of maternal health care service have shown that factors like age, number of living children, education, place of residence, occupation, religion and ethnicity are significantly associated with the use of antenatal care [10].

The level of antenatal care utilization were also found to be high among women with higher economic status, better education, few children, married women and employed women [17, 18].

A community based cross sectional study conducted in Metekel zone, north west Ethiopia, from a randomly selected sample of 1060 women who had at least one delivery in the past five years before the survey, 517 (49.8\%) of the respondents had at least one antenatal care visit during the pregnancy of their last delivery. For the 521 non users, lack of awareness $268(51.4 \%)$ and absence of health problems during pregnancy 213 (40.9) were the main reasons for not attending antenatal care [19].

\section{References}

[1] World health organization (2010): IMPAC (Integrated management of pregnancy and child birth, WHO recommended interventions for improving maternal and new born health. Geneva; World Health Organization.

[2] F. G Cunningham, P. c. Mac Donald, N. F. Gant, et al; "prenatal care," in Williams obstetrics, Appletone and Lange's obstetrician library, $20^{\text {th }}$ edition, 1997.

[3] WHO (2005), what is the effectiveness of antenatal care? (supplement) Copenhagen, WHO regional office for Europe, Health evidence network report; March 23, 2009.

[4] Zanconato G, et al; antenatal care in developing countries: the need for a tailored model. Semin fetal neonatal Med 2006, 11 (1): 15-20.

[5] Rusttam Effend; factor related to regular utilization of antenatal care service among post partum mothers in PasarRebo General Hospital, Indonesia, 2008.

[6] AdamuYandSalihu H, 2002, Barriers to the use of antenatal and obstetric service in Nigeria. Journal of Obstetric and gynecology, 22 (6); 600-603.
[7] World health organization (WHO), the 2005 world health report; make every mother and child count, WHO, Geneva, Sweezerland, 2005.

[8] Central Statstical Agency and ICF international; Ethiopian Demographic and Health Survey 2011, Addis Ababa, Ethiopia and Calverton, Maryland, USA, 2012.

[9] Zein A, Mirkuzie W, Shimels O; Factors influencing antenatal care service utilization in Hadiya zone, Ethiopian Journal of Health science, July 2010; 20 (2): 75-82.

[10] N. Nisar, F. White; factor affecting utilization of antenatal care among reproductive age group women in squatter settlement of Karachi; Journal of Pakistan medical association January 2008.

[11] Mother- baby package; implementing safe mother hood in countries, WHO /FHE/ MSM/94.11, 1994; 24-25.

[12] Kinney M. Kerberk, Black R. et al (2010) sub Saharan African's mothers, newborns and children; where and why do they die? Plos medicine 7; e1000394. Doi; 10.1371 / Journal. Pmed. 1000294.

[13] Nandita P, Donald C, Hermann Z; Health and nutrition; knowledge, attitude and practice of pregnant women attending not attending ANC clinics in western Kenya; Journal of medical case reports. 12013; 13: 146.

[14] Onasoga, Olayinka A, Afolayan; factors influencing utilization of antenatal care service among pregnant women in LTE central Lga, Osun state Nigeria, National HO spital Abuja, NIGERIA, (2012), 3 (3): 1309-1315.

[15] Annam, Hanneke M, Frank O, etal: use of antenatal service and delivery care among women in rural western Kenya, a community based survey. Reproductive health 2006; 3 (2).

[16] Lindsey L, Rob B, Stephenson; utilization of maternal health care service in the department of Matagalpa, Nicaragua. Journal of public health, 2006; 24 (2): 75-84.

[17] Behailu T, Abere G, Yohannes D; Factors affecting antenatal utilization in Yem special woreda, South Western Ethiopia: Ethiopian Journal of Health Science; March 2009; 19 (1):4546.

[18] Fekede B, G/mariam; antenatal care service utilization and associated factors in Jimma town (South West Ethiopia): Ethiopian medical Journal. 2007:45 (2) 123-133.

[19] G. Tura: antenatal care service utilization and associated factors in Metekel zone, North West Ethiopia; Ethiopian Journal of health science. 2009; 19 (2):111-113. 